\title{
POLICY TRANSFER OR POLICY CHURN? INSTITUTIONAL ISOMORPHISM AND NEOLIBERAL CONVERGENCE IN THE TRANSPORT SECTOR
}

\author{
Jason Monios \\ Transport Research Institute, Edinburgh Napier University \\ Merchiston Campus, Edinburgh, EH10 5DT, United Kingdom \\ Email: j.monios@napier.ac.uk
}

This is the pre-published version of the text. The final published paper can be found at:

Monios, J. (2017). Policy transfer or policy churn? Institutional isomorphism and neoliberal convergence in the transport sector. Environment and Planning A. 49 (2): 351-371.

DOI: $10.1177 / 0308518 X 16673367$

\begin{abstract}
While the features of successful policy transfer are well known, there is some evidence that increase in policy transfer is associated with convergence of not just policies but institutional and organisational forms. Institutional isomorphism is often a result of copying organisational form as a way of securing legitimacy rather than seeking successful policy outcomes. It is also influenced by the convergence of the neoliberal paradigm over recent decades which decreases the likelihood of selecting or implementing disruptive policies.

This paper interrogates policy transfer as both a normative process of sharing "best practice" and a mimetic process of copying organisational form in order to secure legitimacy. There is a danger that, rather than focusing on good implementation of existing policies, new policies are continually sought, which is often encouraged by isomorphic institutional forms driven by political motivations to reduce public responsibilities for unsuccessful or unpopular policies.

The aim of this paper is to develop the conceptual tools for analysis of how and when policy transfer becomes policy churn and the role of institutionally isomorphic tendencies in this transition.
\end{abstract}

Key words: policy transfer, institutions, diffusion, neoliberal, convergence, governance, implementation, transport 


\section{Introduction}

Over the last two decades a body of literature has developed on policy transfer, some of the key outputs of which have been based on empirical application to the transport sector. Previous research has established the key features of policy transfer and the factors that facilitate and constrain it. There is some evidence that an increase in policy transfer is associated with convergence of not just policies themselves but institutional and organisational forms. This convergence is influenced by several factors, such as securing legitimacy in the eyes of other organisations as well as the public and the media, linked to the change in many countries from a Keynesian interventionist political paradigm to a neoliberal market-based approach which increases the difficulty of implementing disruptive policies. An unresolved question is whether and how institutional isomorphism constrains the transfer process, increasing the likelihood of failure and leading to an ongoing turnover of policy.

While the institutional literature occasionally mentions policy churn, it remains overlooked in the policy transfer literature. Marschall and Shah (2005; p. 165), drawing on Hess (1999), define policy churn as "when policies are passed that do not satisfy the interests of all stakeholders, . . . the adoption of a policy by a new set of stakeholders, and then subsequent readoption of newer reforms (advocated by another set of stakeholders)." Thus the role of stakeholders and decision makers, as well as popularity and collective agreement are central to the issue: "because each educational problem has numerous possible solutions, and because stakeholders cannot agree on which one would be best, each of them gets applied at some point in time" (Marschall and Shah, 2005; p. 172). This disagreement on which policy is most suitable derives from the difficulty in comparing and benchmarking, thus what is presented as a rational process is in practice open to several influences. According to Peck (2011; p. 6), "learning and diffusion are politically channelled, rather than 'open' processes." In this paper, the focus is on the influence of institutional isomorphism and how the particular way in which it bounds rationality can lead to sub-optimal policy transfer outcomes.

Policy churn is defined in this paper as changing a policy without establishing a clear link between the reasons for failure of the existing policy and how these will be overcome by the new policy. Policy churn is distinguished from policy transfer as it derives not solely from boundedly rational seeking of better policies (the way policy transfer is generally characterised) but from processes of institutional isomorphism. Or to rephrase, the process is boundedly rational but the interest is on the influences that bound it. A new policy may not be randomly selected but it will be chosen from a reduced set of alternatives and possibly while 
decision makers are under pressure to be doing something without sufficient evidence that the change would be better than the current policy. Policy churn can manifest as an unnecessary transition to a new policy instrument rather than simply devoting more resources to the implementation of the current instrument, or indeed solving the underlying cause of the problem. For example, rather than reducing unemployment by policies to create more jobs, seeking to try new policies of incentivised welfare payments (Peck \& Theodore, 2001). In the case of transport, governments prefer to encourage people to change their behaviour voluntarily (i.e. to travel less or by more sustainable modes) rather than using policies such as road charging to make driving less attractive (Marsden et al., 2014) or undertaking the more difficult but ultimately more successful task of reframing the overall discourse on mobility by challenging the pro-car narrative (Schwanen et al., 2012).

In order to maintain conceptual clarity regarding policy churn, it is necessary first to identify at which point on the spectrum churn is likely to occur. In terms of Hall's (1993) three orders of policy, the third order is changing the higher level policy goals, the second order is changing the instruments and the first order is calibration of policy instruments. Howlett and Cashore (2009) expanded Hall's three orders to six: goals, objectives, settings, instrument logic, mechanisms (the term "instruments" is preferred throughout this paper) and calibrations. This typology allows greater nuance, for example maintaining a goal (e.g. reduce negative environmental effects) and objective (e.g. reduce emissions from transport) but changing the instrument logic (preferences for encouraging tax cuts on electric cars or a punitive tax increase on combustion engines). Hall's theory suggests that policy churn takes place mostly in the first and second order, which occur within an existing policy system, while third level change requires an exogenous influence or paradigm change. Using the terminology of Howlett and Cashore, the higher level policy goals and objectives generally remain unchanged but institutional isomorphism can narrow the settings and instrument logic that determine the selection of acceptable policy instruments and calibrations. These are then less likely to be strong enough to succeed, leading to new instruments nonetheless chosen from within the same restricted pool, leading to churn.

So it is at this point of the policy spectrum that institutional isomorphism directs policy churn which manifests primarily at the two lowest levels of instrument and calibration. For example, reducing emissions remains the objective, because changing it would be politically unpopular, but reducing it through electric vehicles gains priority over a reduction in travel (logic), which is difficult to achieve in the absence of stringent disincentives (instruments) 
that are considered politically unacceptable (particularly at the chosen level of calibration). In some cases neither the previous nor the new instrument is expected to succeed but neoliberal governance forms prevent the disruption of the policy setting or logic (see Section 4). This paper explores how the convergence of organisational forms due to increased policy transfer both draws on and feeds into wider processes of institutional isomorphism. The result is an ongoing turnover of the transferred policy instruments, where a succession of new policies are implemented in order to secure and retain legitimacy of policy makers rather than focusing on the lessons of successful implementation that are already well covered in the implementation literature.

The goal is to identify some of the key elements that turn transfer into churn and how the organisational form facilitates or constrains this process. The intention is not to suggest that transfer is really just churn. By identifying factors that influence how policy transfer can become policy churn, the framework developed in this paper can improve the quality and efficacy of policy transfer and help prevent potentially valuable transfer initiatives descending into negative churn effects. The framework will need to be calibrated through empirical testing, subject to the difficulties of measuring, comparing and benchmarking policy (Gudmundsson et al., 2005; Howlett and Cashore, 2009). As many of the key theoretical and empirical outputs on policy transfer have been developed through application to the transport sector, a particular focus is on this area of policy, although the key issues identified and the analytical framework produced are generalizable to other policy contexts.

Section two introduces the concept of institutional isomorphism and its normative, mimetic and coercive forms. This process is occurring for several reasons, with and without policy transfer, leading to a convergence of (particularly neoliberal) organisational forms. Section three defines and critiques the policy transfer process, highlighting how previous work on policy transfer has tended to overlook two aspects. First, how the already existing processes of institutional isomorphism bound the rationality of policy transfer, and second, how policy transfer itself occurs in an institutionally isomorphic way by encouraging the convergence of organisational forms. Section four demonstrates how policy churn results from these processes, whereby the policy transfer process is not as rational as it is sometimes presented, being bounded by influences such as political acceptability (in which neoliberalism plays a large role), the serendipity of policy selection and the role of individual actors, including politicians, planners and experts. Section five derives a framework of ten factors that influence the transition from policy transfer to policy churn, provides empirical 
examples of each and discusses the methodological challenges in research design for a full application of the framework to a longitudinal case. Section six concludes with a research agenda, including the role of politicians, planners and experts, whether there is a trend of the kinds of policies that are more likely to be churned and whether this correlates with a reluctance to devote the necessary resources to implementation.

\section{Institutional isomorphism}

The concept of institutional isomorphism developed out of the structuration of organisational fields, building on the work of Giddens (1979). According to DiMaggio and Powell (1983):

The process of institutional definition, or "structuration", consists of four parts: an increase in the extent of interaction among organizations in the field; the emergence of sharply defined interorganizational structures of domination and patterns of coalition; an increase in the information load with which organizations in a field must contend; and the development of a mutual awareness among participants in a set or organizations that they are involved in a common enterprise (p. 148).

They go on to describe institutional isomorphism, first by distinguishing it from competitive isomorphism, whereby, subject to the assumption of competitive markets, the most efficient solution will emerge due to competition. Institutional isomorphism, by contrast, results from drivers such as the need to seek legitimacy: "Organizations compete not just for resources and customers, but for political power and institutional legitimacy, for social as well as economic fitness" (p. 150).

Three types of institutional isomorphism are identified: coercive, stemming from political influence, mimetic, resulting from uncertainty, and normative, associated with professionalization: "Organizations tend to model themselves after similar organizations in their field that they perceive to be more legitimate or successful" (p. 152). Moreover:

Institutional isomorphic processes can be expected to proceed in the absence of evidence that it increases internal organizational efficiency. . . . Similarity can make it easier for organizations to transact with other organizations, to attract career-minded staff, to be acknowledged as legitimate and reputable, and to fit into administrative categories that define eligibility for public and private grants and contracts. None of this, however, ensures that conformist organizations do what they do more efficiently than do their more deviant peers (p. 153). 
A number of hypotheses are derived from this analysis, predicting that institutional isomorphism is more likely to occur as a result of the existence of factors such as interorganisational dependence, uncertainty between means and end, ambiguity of goals, reliance on academic and professional credentials and the greater centrality of resource supply and greater dependence on a small number of sources for vital resources.

A convergence in transport policy across devolved transport authorities in the UK was identified by Shaw et al. (2009), driven by political pressure to emulate (as the same political party was at that time in power across all of these jurisdictions) as well as limited knowledge or motivation to explore alternatives. The authors suggest (p. 564) that this convergence "seems to reflect the pressures on the devolved administrations to appear legitimate, encouraging lock in to existing strategic frameworks and the opportunistic borrowing of specific policy measures." This suggests evidence of institutional isomorphism, which leads the authors to hypothesise that "devolution and institutional immaturity, coupled with the inexperience of key personnel, promotes isomorphism because of the great uncertainty that it generates." (p564). They go on to state that, while this situation may change over time, "the devolved administrations will continue to operate within a shared organisation field characterised by great uncertainty and an enduring search for legitimacy, suggesting that isomorphic processes will remain a feature of the new territorial politics of devolution" (p564). Some evidence of divergence has in fact appeared in recent years, due to political fragmentation and "nation building" in UK devolved administrations, notably the administration of the Scottish National Party in Scotland (Chaney, 2014). Yet Morphet and Clifford (2014) note that a shared civil service culture across the UK acts to limit policy divergence even between different political parties.

Evans and Davies (1999) draw on Cerny's (1992) use of the competition state ("the state increasingly using new forms of economic intervention intended to marketize the state itself as well as to promote the competitive advantage of national industrial and financial activities within a relatively open world economy" p. 241) to suggest that "the policy agenda of the competition state is where we are most likely to locate examples of policy transfer" (p. 373). This finding reflects the work of Timms (2011) regarding the evolution of EU transport policy to a more economical than sustainable bent, i.e. transport investment is good because it leads to economic development (cf. Stead, 2008). Isomorphism thus represents the increasing similarity of state forms, the better to be co-opted into globalised neoliberal norms. From 
here, what is politically acceptable becomes narrower (Peck, 2001) and any real disjunctive policy intervention, such as one that threatens economic growth, becomes less likely.

On the other hand, it is important not to overemphasize convergence, as a focus on such broad trends can mask a variety of geographically scaled governance forms (Marsh and Sharman, 2009; Heichel et al., 2005; Peck et al., 2009). Jarvis's study of the Hong Kong education system revealed that it is possible to subvert convergence processes to produce "forms of regulatory or even organizational performativity that 'comply' without complying" (p. 250) because, drawing on Weiss (2012), neo-liberal competition states and developmental regulation states may exist simultaneously. The latter exist through "the politics and ceremony that pervade much modern organizational life" (DiMaggio and Powell, 1983, p. 150 quoted approvingly by Jarvis). In other words, it is the peopled organisation that matters, even if official institutional forms appear isomorphic. This suggests more evidence of the need for a structure/agency approach, which will be taken up in Section 4.

In any case, the point is not necessarily that all organisations and policies have converged into some dastardly neoliberal cabal, but that the dominant neoliberal paradigm, according to which the role of the state is seen as less interventional, influences institutional structure and the kind of policies selected. Yet it can work in counter-intuitive ways. As shown by Docherty \& Shaw (2011), the UK Labour government (1997-2010) had large majorities in its first two terms and began with rather bold sustainable transport policy goals. Yet a lack of implementation led to ever more policy documents being produced, which, despite their retention of the same policy goals, in fact changed and watered down the actual policy instruments. By contrast, Headicar (2009) notes that the UK Conservative government (19791997) had very little in the way of published transport strategy but they still made significant changes to transport governance across the UK, including widespread privatisation of infrastructure and operations and centralisation of planning responsibilities. According to Docherty and Shaw (2011; p.232): "It is difficult to avoid the conclusion that the DfT might have deployed its resources more effectively by actually delivering policy rather than continually seeking to rework it."

As a supranational institution, the EU uses isomorphism to obtain legitimacy, which it lacks because of its democratic deficit (Radaelli, 2000). Legitimacy may also be sought for policies that already exist, whereby a brand new policy is likely to be more acceptable if it is presented as being drawn from "best practice" elsewhere. Using DiMaggio and Powell's three sources of institutional isomorphism, Radaelli identifies that, in the case of the EU, 
mimetic processes derive from the need for legitimacy, whereas normative pressures are found from the group of policy experts referred to earlier in the paper, "a common cognitive base and a shared legitimization of occupational autonomy which make organizational structures similar one to another" (p. 28).

Moreover, while Radaelli (2000) notes that coercive institutional isomorphism is less likely in the EU, in a related analysis focusing on the motive for transfer (cf. Dolowitz and Marsh's continuum from voluntary to coerced) Bulmer and Padgett (2004) suggest that in the EU policy transfer does not necessarily occur in domestic policies like transport instruments. The most successful transfers are actually the coerced and negotiated ones regarding macro level finance mechanisms, which occur in the "more highly institutionalized governance regimes" (p. 103), whereas "in the very weakly institutionalized mode of governance by facilitated unilateralism, extant policy preferences and practices may play a more decisive role" (p. 124). Therefore neoliberal isomorphic tendencies may be more prevalent in the design of higher level economic structures than lower level "on the ground" issues like transport, where local decisions will remain important.

Similarly, Peck (2011) addresses international institutions pushing neoliberal reforms on individual countries on the basis that it "worked elsewhere." While Marsden et al. (2012) find little evidence for coercive policy transfer in developed countries, supranational organisations such as the World Bank and the IMF influence policies of privatisation of transport industries in developing countries, for example bus rapid transit (BRT) (Paget-Seekins, 2015) and the increased role of private operators in the port sector (Wilmsmeier and Monios, 2015). Even in developed countries similar issues may be at play, whereby local politicians may control the level of coercion by pushing for more or less policy transfer depending on their political motives and public acceptability. These issues can be related to concerns raised by Peck (2011) and Marsden et al. (2012) regarding evaluating and selecting appropriate policies to transfer from elsewhere that are often based on the paradigm or worldview of those doing the transfer rather than a neutral value-free process.

The role of neoliberalism in the policy process is defined for the purposes of this discussion as seeking "to maximise the role of market mechanisms in public policy and service provision" (Docherty et al., 2004; p. 257). In recent decades, the provision of transport services and to a lesser extent the development of infrastructure have been increasingly outsourced to the private sector, sometimes through regulated franchise monopolies (e.g. the right to operate all passenger trains within a geographical area) and in 
others through an open competitive market where the public sector operator competes directly with private operators or withdraws from the market, perhaps running only those unprofitable services that are unattractive to private operators but deemed as socially necessary by the government (e.g. rural bus routes). A full discussion of the role of neoliberalism in transport policy is beyond the scope of this paper, where the focus is on how institutional isomorphism (on which neoliberalism is only one, albeit important, influence) leads to a limitation in the kinds of policy instruments selected. It is interesting that Docherty et al. (2004) identified some evidence of a reengagement by government in transport policy, potentially a move away from marketization, yet, looking back now at the weakness of the policy instruments selected (see discussion of behavioural change nudges rather than disincentives in Section 4) it is argued here that these attempts took place within a neoliberal paradigm that limited the range of acceptable actions. For example, Aldred (2012; p. 95) demonstrates that "cycling became embedded in public policy only after policy-making had been variously outsourced to private, quasi-private, and voluntary organisations." Thus, rather than introducing strong policy instruments, the state relied on non-state organisations to deliver change, avoiding the need to introduce unpopular policies, devote resources or modify the wider policy setting by disincentivising driving.

Western neoliberal political forms are not the only governance structures that influence policy choices, nor do they always produce similar outcomes, as shown by evidence from the Global South (Parnell and Robinson, 2012). Paget-Seekins (2015) shows how the introduction of private BRT schemes has been used in South America to overcome a fragmented and unregulated public transport sector that was providing low quality services and leading to congestion and emissions problems. By restructuring the bus market through the construction of route based monopolies contracted to private operators, the government was able to regulate service levels and quality, and the new system also provides workers with collective action opportunities to protect their interests unavailable in the previous informal market. On the other hand, small local operators are forced out of the market and the state now pays subsidy to large private operators, so while neoliberalism can in some cases counterintuitively lead to progressive goals, these are still achieved within market-based assumptions and norms. 


\section{Policy transfer}

The seminal papers by Dolowitz and Marsh (1996, 2000) drew on earlier scholars such as Rose (1991, 1993) and Bennet (1991) to establish the framework of policy transfer that still forms the basis of research in the field, according to seven key questions:

1. Why do actors engage in policy transfer?

2. Who are the key actors involved in the policy transfer process?

3. What is transferred?

4. From where are lessons drawn?

5. What are the different degrees of transfer?

6. What restricts or facilitates the policy transfer process?

7. How is the process of policy transfer related to policy "success" or policy "failure"?

One of the key issues raised by Dolowitz and Marsh beyond the simple framework questions are the necessary distinction between voluntary and coercive transfer, a point taken up by later authors, some of whom also investigate the processes and relationships between the key actors, in particular the roles of policy entrepreneurs/experts and supra-national institutions such as the EU (e.g. Stone, 2004). Objects of transfer can be a range of things: policy goals, structure and content; policy instruments or administrative techniques; institutions; ideology; ideas, attitudes and concepts; and negative lessons, while constraints on transfer include policy complexity, past policies and institutional structure.

The four degrees of transfer identified by Dolowitz and Marsh are copying, emulation, mixtures and inspiration. Deeper questions asked include (Dolowitz and Marsh, 2000; p. 7):

Do different actors get involved at different stages of the policy transfer process? When is policy transfer likely to occur within the policy-making cycle? How does the type of transfer vary depending upon when it occurs within the policy-making cycle? (For example, is it more likely to be inspirational transfer during the agenda-setting stage while a mixture during the policy-formulation stage?) Do different agents of transfer engage in different types of transfer? (For example, do politicians attempt to copy "foreign" models while bureaucrats work at developing new programs based upon a mixture of different ideas and programs?)

The authors also explore the relation between the location on the continuum between voluntary and coerced transfer, and the success or failure of a policy, identifying uninformed, incomplete and inappropriate transfer. 
The framework has been explored and expanded by later authors, specifically in the field of transport such as Marsden and Stead (2011). Timms (2011) added an important top-down and bottom-up disaggregation of these issues, illuminating the critical need to be aware of the perspective, i.e. whose motive is the transfer and who benefits? An excellent summary of the key aspects of policy transfer in the field of transport is provided by Marsden et al. (2011; p. 510), based on a comprehensive review of 30 transport policies across a range of 11 cities:

The overwhelming majority of searches for new policies are spontaneous, bottom-up actions driven either by identified shortcomings in urban strategies (which will not be solved by applying current tools) or by curiosity and a desire for continual improvement amongst staff. Some searches are driven by political intervention, legislation or the availability of funding streams. Political intervention in particular can provide impetus to a search process. Local government officials are the dominant players involved in both the initiation and search for new policies (though this finding may have been influenced by our sampling approach). Politicians, residents and interest groups play a role in initiating the search for new policies whilst consultants and suppliers are more engaged in the consideration of different options.

Two of the key aspects of relevance to this paper, derived from Dolowitz and Marsh and addressed in more detailed by later authors (especially Peck, 2011), are the role of politics and a focus on what is transferred. Robertson (1991; p. 55) suggests that: "policy lessons from abroad often are put forward as politically neutral truths. Beneath this . . . adversaries are just as often using such lessons as political weapons." Indeed, Dolowitz and Marsh (1996; p. 355) express concern that "policy transfer is underpinned by pluralist assumptions and the key question of whose interest is served by this process goes unasked." According to Haas (1980): "the hallmark of complex interdependence is uncertainty . . . International collaboration ... is an attempt to reduce uncertainty."

A perhaps unfairly negatively described group of external consultants acting as policy experts facilitates this process, described by McCann and Ward (2009; p. 181) as "charismatic consultants who trek from place to place with their policy solutions in their laptop hard drives" and by DiMaggio and Powell (1983) as "almost interchangeable individuals who occupy similar positions across a range of organizations" (p. 152). This is supported by the need to demonstrate that policy was transferred, resulting in a cascade of project and policy reports. The marketization of the state (see section 2), allied to the shrinking of the state in many developed countries means that the expertise to develop or transfer policy is no longer available in government organisations which has led to a reliance in recent years on external experts. The difficulty is that planners and politicians making the 
final decision do not always have the expertise to judge the information presented. Thus institutional isomorphism serves to further bound the rationality of decision makers.

As part of the normative process of professionalization, the use of external knowledge can be attractive to politicians not only for its intrinsic value but because it helps create distance and thus deflect blame. This is a similar process to the creation of quangos (quasi nongovernmental organisations such as advisory environmental bodies or regional transport organisations) which can be used to create an 'objective' assessment of needs in a particular policy area based on policy transfer and expert opinion, but without authority for implementation and their funding and very existence subject to the whims of changing governments, meaning that such recommendations are commonly diluted, delayed and frequently not implemented by those with agency (e.g. governments). While the use of expert knowledge has received some attention (e.g. Naess et al., 2013; Tennøy et al., 2015), its role in the relationship between politicians and planners requires further research.

O’Dolan and Rye (2012) identified the two-stage nature of policy transfer. Many actors involved in the first stage (gaining the knowledge) are external experts rather than the actual implementers themselves, therefore a second stage is often needed for these experts to transfer that knowledge and indeed the motivation to public sector planners and policymakers. Similarly, the learning process is more complex than simply experts deciding on what is best and therefore instituting isomorphic policies, as policy makers already have their own policy preferences (Dunlop, 2006), and, as noted by Marsden and Stead (2011), policy makers may be less involved in the first stage of policy identification but strongly influence the transfer that actually occurs, again leading back to the temporal approach advocated by Dolowitz and Marsh (2000). Moreover, the kind of learning transferred can depend on the wider institutional setting (Lodge, 2003), including aspects such as communication and information sourcing, sharing and interpretation (Wolman and Page, 2002). Levi-Faur and Vigoda-Gadot (2006) and Marsh and Sharman (2009) explored the difference between policy transfer and policy diffusion, the latter being a more natural and less proactive process.

Marsden et al. (2011) identified the key motivations for transport policy transfer as "strategic need" and "project or policy collapse". Regarding the former, they state that "policy failure occurs where it is apparent that continuing with current policies will not lead to the achievement of the organisation's objectives." However, just as some critics suggest that it is difficult to ascertain when a policy has actually been transferred (as opposed to a 
natural evolution in the policy making process), it is also unclear how to decide that a policy has failed as opposed to a situation where its implementation has not been adequately resourced. Moving on to the second category, the authors identified cities where a planned project had failed and a replacement was sought urgently by politicians seeking to limit criticism. This could be a factor to increase the likelihood of churn, as the need for a new policy is agreed before sufficient analysis has taken place. An additional category noted by the authors is legitimization, tying in with earlier comments about political legitimacy, and a related category of "enhanced support", in some cases to accelerate developments that have already been planned. Here again, political need is driving the policy decision.

Inadequate sources of information represented a central difficulty identified in the research of Marsden et al. (2011). To begin with, information is often located "informally and sometimes quite randomly" (p. 508), and interview respondents stated that there is often too much information, and, crucially, the quality of the information is difficult to verify. The result is that specific individual contacts are relied upon rather than objective analysis, highlighting the importance of individuals. Similarly, transport policy convergence identified between Australian states by Bray et al. (2011; p. 531) has occurred despite "no documented evidence that the performance of previous strategies has been reviewed and actions in subsequent strategies demonstrated to be superior and able to achieve the objectives set for them." This points to other reasons for policy transfer than an objective review of the evidence, possibly political motivations or convergence due to uncertainty.

The analysis of the transfer of urban mobility management policies between European cities by Rye et al. (2011) revealed the serendipity of policy transfer, heavily dependent on the interests and enthusiasms of specific actors. It means that seeking and finding a new policy in the first place may not be an exhaustive search, and the lack of good information makes it difficult to validate if it is actually a suitable policy, which leads to a higher likelihood of inappropriate transfer (or indeed incomplete or uninformed). This leads to a higher risk of failure, which brings a need for a new policy therefore high risk of churn. As Marsden et al. (2011) point out, "unsystematic search" and "quality of the evidence base" are barriers to policy transfer. These can also be interpreted not solely as barriers but as reasons why a policy may still transfer but do so inappropriately or incompletely, leading to failure and the potential for churn. Both theoretical and empirical studies suggest the dangers of inappropriate and incomplete policy transfer, but overlooked so far has been the issue of how this can lead to an ongoing process of continual transfer with its own negative effects. 


\section{Policy churn}

Policy transfer considered as institutional isomorphism manifests as convergence, due to factors such as those identified by Bennett (1991): emulation, elite networking, harmonization and penetration by external actors. What is not considered is the tendency towards an ongoing turnover of policy. Thus the isomorphism is related to institutions such as organisations, processes and policy types, but not necessarily to stability in individual policy instruments and programmes. Is policy transfer more about looking for good policies and knowledge or merely gaining legitimacy? This section will examine the relationship between institutional isomorphism and policy churn.

Peck (2001) contends that in a modern state rescaled by a neoliberal political agenda, “there is always another local 'solution' over the horizon to emulate" (p452), leading to an increase in policy turnover: 'the technocratic lubrication of channels for 'policy transfer' and 'policy learning', means that a dynamic of almost perpetual reform is generated" (p452). Maintaining the previous definitions of different aspects of policy that may be churned, this dynamic is observed primarily in policy instruments. Observers of the last decade of transport policy in the UK would recognise something of this "continued churning of policy strategies" that diffuse reforming energy and can easily lose sight of the original policy goals. Such policy churn and reorganisation of governance scales can also lead to "objective fatigue" (Docherty et al., 2007). Having said that, some difference in higher level policy goals can be seen over time, especially through political cycles; for example, in the UK, the previous motorway building "predict and provide" approach of the Conservative government gave way to a narrative of sustainable transport during the Labour years. Yet as mentioned earlier, despite a lot of effort on narrative building, policy instruments and the level of calibration employed remained rather weak and tended to be churned without changing the policy goal even while tacitly admitting that it would not be reached. The neoliberal system did not prevent a change in policy goal between administrations, but rather prevented the deployment of policy instruments of sufficient impact to achieve the new goals.

A full analysis of the structure and agency approach (advocated by Evans and Davies, 1999) is a larger topic beyond the direct scope of this paper, but some key aspects of the theory are relevant here, such as how the uneven hollowing out (Rhodes, 1994) and filling in (Jones et al., 2004; Goodwin et al., 2005) of institutions has created asymmetrical acting capacity. MacKinnon et al. (2010) argue that any consideration of the role of actors requires 
an approach that can assess structure and agency, and they note that Jessop (2001) is critical of Giddens's (1984) structuration theory for "assuming that a particular structure is equally constraining or enabling for all actors” (p.274). Jarvis (2014) noted that institutional forms may ostensibly converge but that does not mean that individuals are unable to work within it. Committed activists can implement disruptive policy instruments, but in most cases they are still required to work within the dominant neoliberal paradigm. For example, Henderson (2011) showed how cycling activists overcame a pro-car road space allocation system, although it was achieved counter-intuitively by building an alliance with property developers who see value in improving urban space for their intended client market.

Moving on towards the emergence of policy churn, DiMaggio \& Powell (1983; p. 152) wrote that "the ubiquity of certain kinds of structural arrangements can more likely be credited to the universality of mimetic processes than to any concrete evidence that the adopted models enhance efficiency." This lack of evidence may be a result not simply of a lack of monitoring but the way in which it is done. According to Meyer and Rowan (1977): "the more an organization's structure is derived from institutionalized myths, the more it maintains elaborate displays of confidence, satisfaction, and good faith, internally and externally." (p358). These displays include "rationalized rituals of inspection and evaluation" (p359).

Oliver (1991) suspects that institutionalist scholars have exhibited too great a focus on passive acquiescence to isomorphic pressures, which represents only one response to institutional pressure, the other four being compromise, avoidance, defiance or manipulation. For example, the process of disguising nonconformity exhibited in Hong Kong education institutions as revealed by Jarvis (2014). Stead et al. (2008) demonstrate the importance of understanding the often different institutional context of the country receiving the policy, as supportive environments and cultural norms may present the success of the policy, yet DeJong and Geerlings (2005) show that even transferring policy between similar institutional environments is no guarantor of success. Viewing from different perspectives can also be illuminating here; for instance, in some cases politicians manipulate the new policies that their experts and civil servants bring them, in order to fit their needs and not expose them to anything deemed undesirable, such as the need for new investment or the risk of failure leading to negative media coverage.

Attempting to influence institutions consciously is also subject to a number of limitations, as summarised by Pierson (2004): many effects will be unexpected and potentially longer 
lasting than the current problem, actors or organisations may change or disappear over time, and the application of generic solutions may not fit the problem. Various frameworks have been put forward to model the process of institutional change (Monios and Lambert, 2013). Part of this discussion includes the role of political organisations, which attempt to exert influence but do not have the same agency enjoyed by, for example, economic organisations.

Policy churn can result from a lack of a cohesive and consistent agenda (Marschall and Shah, 2005), in some cases the result of informal elites governing city policy from an economic development agenda and succeeding in preventing more progressive policies from gaining traction. This political aspect is particularly pertinent, especially with regard to the recognition that it can take different forms. Marschall and Shah (2005) highlight the importance of political entrepreneurs in preventing policy churn and enabling consistency, while studies of policy implementation note the role of political champions to drive a new policy (e.g. Ison and Rye, 2003). Yet political leadership can equally be about implementing an unpopular but successful policy (e.g. congestion charging) as it can be about major investment in vanity or civic pride projects (e.g. high speed rail). Leadership can also come from outside the political class, through lobbyists and activists, as noted above. On the other hand, political leadership is not necessarily the result of a single individual but can be an incremental process involving many actors (Isaksson and Richardson, 2009). Similarly, Marsden and Stead (2011) note that political will is potentially the most important element in terms of "who does the transfer" and can override technical recommendations from planners. That is why this paper widens the discussion to political structure and the role of isomorphism in providing to some degree an illusion of political competence and providing fertile conditions for policy churn. Meyer and Rowan (1977; p. 346) note that “institutionalised rationality becomes a myth with explosive organising potential."

A recent example of this aspect of monitoring as performance is shown in benchmarking of e-government in the EU by Codagnone et al. (2015; p. 305), whereby "High scores in EU benchmarking have contributed to increasing the institutionally-perceived quality but not necessarily the real quality and utility of e-government services." This relates strongly to the ceremonial monitoring mentioned above, and means that if policy success is not being monitored effectively, then deciding on whether or not a policy is working and whether or not a new policy is needed can have no empirical basis and makes churn more likely. In the transport sector, Mononen and Leviäkangas (2016) identify the difficulties in monitoring transport indicators such as safety performance, while Gudmundsson et al. (2005) identified 
several difficulties with benchmarking of policy due to differences from the original private sector application of benchmarking. Challenges include the service rather than product nature of transport, culturally dependent perceptions and a lack of data on external effects. Such complications mean that it can be difficult to ascertain if a policy instrument has been successful and whether reasons for perceived failure would be overcome by the new proposed policy.

The competition state seeks where possible to achieve policy aims through marketization and outsourcing rather than through direct intervention which involves investment, staffing and time, as well as the responsibility in the media for lack of performance. Isomorphism means that what is politically acceptable becomes narrower and disjunctive policy intervention becomes less likely. Policy transfer is not a neutral process but socially constructed based on paradigms (e.g. neoliberal or Keynesian) so it is not necessarily the seeking of best practice but for other reasons that policy is transferred: "it can be difficult to isolate deliberative learning from other forms of emulation and transfer. . . . the near impossibility of rationally determining 'success' or 'failure' outside the framework of particular policy paradigms and belief systems means that learning behaviour remains in the eye of the beholder" (Peck, 2011; p. 787). Using transport policy as an example, the move from a Keynesian to a neoliberal paradigm in the 1980s meant that policies seeking to disrupt the status quo by, for instance, giving road space to cyclists, are deemed unacceptable therefore behavioural incentives are preferred. Is that because objective study has shown that these incentives are more effective than investing in segregated cycle paths or because these are the only measures politicians will allow, due to the neoliberal paradigm dominating discourse that does not see the role of government as interventionist and does not want to face criticism in the media?

Marsden et al. (2014; p. 72) showed that behaviour change incentives (so-called "smarter choices") to reduce demand for transport continue to be preferred in the UK to more stringent disincentives (e.g. road charging to reduce driving, using land use planning to prevent sprawl) even in the knowledge that they will not achieve the stated policy goals, but their choice of instruments is constrained by "normative ideas about what constitutes legitimate attempts to influence behaviour." This leads to outsourcing behaviour influence instruments (e.g. Aldred, 2012 on outsourcing cycling policy instruments to voluntary organisations) and a reluctance to modify the overall policy paradigm (Tennøy, 2010; Cass \& Faulconbridge, 2016). According to Goulden et al. (2014; p. 144): "it creates an illusion of choice, seeking to 
achieve collective goals without directly challenging the neoliberal paradigm." Such strategies result from both the political unacceptability but also the reluctance to risk economic growth by reducing infrastructure and housing construction. Thus, using the terminology of Howlett and Cashore (2009), instruments and calibrations may be churned within a fixed domain of settings and logic. An example of churning at the level of calibration without changing the system logic is the serial modification of UK subsidy programmes for modal shift of freight from road to rail, progressing from Track Access Grant (TAG: established in 1993) to Company Neutral Revenue Support (CNRS: 2004-2007) to Rail Environmental Benefit Procurement Scheme (REPS: 2007-2010) and then Modal Shift Revenue Support (MSRS: since 2010) (Monios, 2014).

Lodge (2003; p. 161) outlines the many institutional conditions that make evaluation and self-correction difficult, concluding that "policy transfer and learning do not constitute 'rational decision-making' in terms of a complete evaluation of all possible policy options. Rather, they represent limited searches for templates that appear more legitimate, appropriate, or successful." According to Marsden et al. (2012; p. 905, 913): "search parameters are significantly influenced by preconceptions of the nature of the preferred solutions. . . Nowhere was the motivation to consider new policies a value-neutral search for the best solution." While policy search is not random, neither is it purely rational. Using the example of public transit development in Chicago, Farmer (2011; p. 1156) shows how the competition state prioritises "megaprojects and infrastructure that help business gain competitive advantages and keep them connected within global networks as well as providing financing and amenities for gentrification, tourism, and cultural consumption." In order to legitimise such projects, the use of quantitative modelling and cost-benefit analysis (CBA) represent a preferred analytical technique within the neoliberal paradigm (see Banister, 2011 on the use of the value of time in CBA). Such large projects are better categorised as civic pride (or political vanity) projects rather than policy churn, but their motivations derive from a similar background. Political pressure may be used to encourage a positive CBA or, alternatively, to ignore the CBA result and approve a project anyway (Docherty et al., 2007).

\section{Developing a framework for identifying a movement from transfer to churn}

From the preceding analysis, the key points that are likely to lead to churn can be identified. From the bottom-up perspective: serendipity of transfer, difficulty evaluating evidence, the central role played by external policy entrepreneurs and their influence (or not) 
on civil servants and politicians. Looking from the top down, politicians apply political pressure for expedient change while reluctant to break fully with past policies. Potentially linking these two perspectives and requiring further research is the relationship between isomorphic organisational forms, obtaining funding from central/national or international organisations and securing legitimacy in both government and the media. Transferred policies and ideas are not politically neutral, and the literature highlighted concerns regarding whose interests are served by transfer. Isomorphic institutions are potentially more able to be coerced by political expediency. DiMaggio and Powell predict that institutional isomorphism is more likely to occur as a result of the existence of factors such as inter-organisational dependence, uncertainty between means and end, ambiguity of goals, reliance on academic and professional credentials, and the greater centrality of resource supply and greater dependence on a small number of sources for vital resources.

The framework of key aspects likely to lead from policy transfer to policy churn is presented in Table 1. Some of the factors are familiar from the policy implementation literature, a full analysis of which is beyond the scope of this paper (for good overviews see Timms, 2011; Cerna, 2013). Similarly, the spatial planning literature (again, beyond the scope of this paper but see Hrelja, 2011 and Newman, 2008) demonstrates the gap between what is written in policy documents and strategies and the day-to-day decision making and implementation "on the ground." The crossover between these bodies of literature gives additional weight to the hypothesis that good implementation will reduce the need for policy transfer and hence churn. While policy transfer and policy implementation are generally considered separate if related fields of enquiry, perhaps their interdependence is not considered closely enough. Some of the key requirements for successful policy implementation (valid link between cause and effect, sufficient resources, political leadership) demonstrate the close link between the two processes. Therefore, the most important question to ask in order to avoid churn is: is the current policy instrument unsuccessful because of the policy design or due to a lack of any of the requirements for good policy implementation, and is it proven that the new policy does not exhibit similar weaknesses? Future research needs to explore in more detail the link between policy design, policy implementation and policy transfer. Any weakness within this three-part framework has the potential to lead to policy churn.

The factors in this framework are the parameters against which to gather empirical evidence for the analysis of a process of policy churn. They are influential factors that may 
manifest in different ways in different cases, and not all will necessarily be present in each case of policy churn. The empirical examples provided in the table are indicative based on empirical work in the transport sector, but they could equally be drawn from other policy areas such as health or education. Thus a full empirical application of all factors of the framework to a single case could be produced in a number of sectors. 
Table 1. Framework of factors leading from policy transfer to policy churn

\begin{tabular}{|c|c|c|c|}
\hline No. & Factor & Example in the transport sector & How it may lead to churn \\
\hline 1 & $\begin{array}{l}\text { Lack of rigorous testing of } \\
\text { whether status quo has failed } \\
\text { and if so whether it was due to } \\
\text { the policy itself or poor } \\
\text { implementation. }\end{array}$ & $\begin{array}{l}\text { Difficulties in monitoring transport } \\
\text { system indicators such as safety } \\
\text { performance (Mononen and } \\
\text { Leviäkangas, 2016). }\end{array}$ & $\begin{array}{l}\text { Poor implementation of existing policy and } \\
\text { higher likelihood of seeking a new policy } \\
\text { that seems cheaper or easier. }\end{array}$ \\
\hline 2 & $\begin{array}{l}\text { Politicians reluctant to devote } \\
\text { resources or take increased } \\
\text { public responsibility. }\end{array}$ & $\begin{array}{l}\text { Outsourcing pro-cycling initiatives to } \\
\text { voluntary organisations (Aldred, 2012). }\end{array}$ & $\begin{array}{l}\text { Poor implementation of existing policy and } \\
\text { higher likelihood of seeking a new policy } \\
\text { that seems cheaper or easier, which is likely } \\
\text { to fail for the same reason, therefore churn. }\end{array}$ \\
\hline 3 & Serendipity of transfer. & $\begin{array}{l}\text { Transfer of mobility management } \\
\text { programmes from one city to another } \\
\text { based on the interest of individual } \\
\text { stakeholders (Rye et al., 2011). }\end{array}$ & $\begin{array}{l}\text { Higher likelihood of inappropriate or } \\
\text { incomplete transfer, therefore failure } \\
\text { therefore churn. }\end{array}$ \\
\hline 4 & $\begin{array}{l}\text { The central role played by } \\
\text { external experts as policy } \\
\text { entrepreneurs and their } \\
\text { influence on civil servants and } \\
\text { politicians. }\end{array}$ & $\begin{array}{l}\text { Strong role played by academics and } \\
\text { consultants through EU-funded project } \\
\text { networks (O’Dolan \& Rye, 2012). }\end{array}$ & $\begin{array}{l}\text { External experts more likely to promote } \\
\text { similar policies which may be positive but } \\
\text { have the potential for inappropriate } \\
\text { transfer, therefore failure therefore churn. }\end{array}$ \\
\hline 5 & $\begin{array}{l}\text { Lack of rigorous testing of } \\
\text { likely success of new policy } \\
\text { (partly due to lack of } \\
\text { information). }\end{array}$ & $\begin{array}{l}\text { Difficult to gather benchmarking data } \\
\text { on external effects of a proposed } \\
\text { transport scheme (Gudmundsson et al., } \\
\text { 2005). }\end{array}$ & $\begin{array}{l}\text { Higher likelihood of inappropriate or } \\
\text { incomplete transfer, therefore failure } \\
\text { therefore churn. }\end{array}$ \\
\hline 6 & $\begin{array}{l}\text { Politicians apply political } \\
\text { pressure for expedient change } \\
\text { due to policy collapse } \\
\text { (coercive pressures). }\end{array}$ & $\begin{array}{l}\text { Funding withdrawn at a late stage for a } \\
\text { tram scheme led to a fast-tracked bus } \\
\text { improvement scheme (Marsden et al., } \\
\text { 2011). }\end{array}$ & $\begin{array}{l}\text { Rushed policy transfer therefore higher } \\
\text { likelihood of inappropriate or incomplete } \\
\text { transfer therefore failure therefore churn. }\end{array}$ \\
\hline 7 & $\begin{array}{l}\text { Uncertainty brings more } \\
\text { isomorphic institutions and } \\
\text { monitoring becomes more } \\
\text { ceremonial than useful } \\
\text { (mimetic pressures). }\end{array}$ & $\begin{array}{l}\text { Convergence of transport governance } \\
\text { forms and policies across the devolved } \\
\text { jurisdictions within the UK (Shaw et } \\
\text { al., 2009). }\end{array}$ & $\begin{array}{l}\text { Success of policy not objectively assessed } \\
\text { therefore higher likelihood of poor } \\
\text { decisions therefore failure therefore churn. }\end{array}$ \\
\hline 8 & $\begin{array}{l}\text { Range of what is acceptable } \\
\text { becomes narrower (normative } \\
\text { pressures). }\end{array}$ & $\begin{array}{l}\text { Policies that reduce travel are less } \\
\text { acceptable than funding for electric } \\
\text { vehicles that reduce emissions without } \\
\text { reducing travel (Marsden et al., 2014). }\end{array}$ & $\begin{array}{l}\text { Becomes more difficult to bring in a totally } \\
\text { new and disruptive policy (e.g. cycle } \\
\text { lanes). }\end{array}$ \\
\hline 9 & $\begin{array}{l}\text { Greater centrality of resource } \\
\text { supply and/or dependence on a } \\
\text { small number of sources for } \\
\text { vital resources (e.g. EU funds } \\
\text { or national funds). }\end{array}$ & $\begin{array}{l}\text { EU funding for multi-nation transport } \\
\text { policy transfer projects (Timms, 2011). }\end{array}$ & $\begin{array}{l}\text { Similar to } 8 \text {, also limits range of acceptable } \\
\text { policies, increases selection of similar } \\
\text { policies which may not be appropriate for } \\
\text { each case. }\end{array}$ \\
\hline 10 & $\begin{array}{l}\text { Politicians reluctant to break } \\
\text { fully with past policies }\end{array}$ & $\begin{array}{l}\text { Reluctance to reduce spending on } \\
\text { infrastructure due to economic growth } \\
\text { priorities (Marsden et al., 2012). }\end{array}$ & $\begin{array}{l}\text { Rather than implement a new policy, } \\
\text { continue with a new version of the old } \\
\text { failing policy or a combination of both. }\end{array}$ \\
\hline
\end{tabular}


The factors in the framework already suggest some features of the kinds of policy instruments more likely to be churned: less infrastructure based therefore easy to remove (e.g. bus lanes), more expensive therefore attractive to discontinue (e.g. subsidies for modal shift) or less popular (e.g. bike lanes). Yet there are numerous influences that determine individual cases, therefore empirical testing is required. In some cases, the long-term nature of major infrastructure investment means that politicians may prefer short-term policy instruments (e.g. investment in electric vehicles for government departments), but in other cases governments may find it more politically acceptable to fund a large project (e.g. high speed rail) rather than many small investments. Policy churn can result from policy instruments that were unsuccessful in meeting their goals, but also purely because they were unpopular and therefore decision makers realised that they would not achieve their goals so the calibration passes through several iterations before ever being implemented, e.g. The UK Labour government's plan for road charging which was continually postponed and never implemented. Some policies are successful yet popular with some groups of voters and unpopular with others, thus the likelihood of being churned will depend on the interests of the politician making the decision (e.g. congestion charging or bus lanes).

Applying the framework developed in this paper to empirical cases will be subject to the methodological challenges of measuring, comparing and benchmarking policy discussed in section 3 (Gudmundsson et al., 2005; Howlett and Cashore, 2009). Howlett and Cashore (2009; p. 38) recognise the dependent variable problem in studies of policy, leading "many scholars to inadvertently conflate several distinct change processes present in specific elements of policy." In order to provide greater clarity between processes, their six-point policy framework discussed in section 1 distinguishes between "goals (more abstract), objectives (less abstract), and settings (least abstract)." Therefore, the framework developed in this paper will need to be calibrated through empirical testing in order to determine not only which kinds of policies are more subject to churn, but also to what degree it is mostly policy instruments being churned rather than higher level objectives and top level policy goals. The analysis in this paper suggests it will mostly be instruments, as institutional isomorphism places constraints on changing goals and objectives, but empirical examination is required.

Policy churn was defined earlier in the paper as changing a policy without establishing a clear link between the reasons for failure of the existing policy and how these will be overcome by the new policy. Case selection presents an initial difficulty, as a longitudinal 
perspective would be ideal but once a suitable candidate of churn has been identified, it may be difficult to obtain evidence of what happened regarding policy design, implementation and transfer in the years before. Such data can be gathered through interviews and documents but gaps may remain. However, the increasing availability of documents and news archives online makes the task easier than in the past. Moreover, examining the progress of a particular policy area over time must also recognise how a range of policies affect each other in their relative appropriation of resources from a single source (e.g. the success of different transport policies depends partly on their share of the transport budget).

Evans (2009) and Heichel et al. (2005) identify several differences in the research approaches applied by scholars in the study of policy and discuss the implications for drawing firm conclusions with regard to policy transfer and diffusion. For example, the difficulties selecting the limited field of study to a policy area, a single policy goal or single instrument, or the difficulty of interpreting results when some aspects (e.g. policy goal, setting, instrument, calibration) converge and others diverge. As noted above, selecting the time dimension for a study can also be difficult and making clear measurements of before and after. These methodological challenges are common to social science researchers and are certainly present in the study of policy transfer, but they are perhaps more serious in relation to policy churn because ideally a succession of transfers or policy changes should be followed in order to trace the churn process, which would require a longer duration and increase the difficulties of data acquisition.

\section{Conclusion and research agenda}

In concluding, it is necessary to reiterate that the intention of this paper is not to suggest that policy transfer is really just churn. The objective is that, by identifying factors that influence how policy transfer can become policy churn, this framework may help to improve the quality and efficacy of policy transfer.

Policy transfer is a necessary process, and indeed it is occurring regardless of whether we study it or not. Good policy transfer improves the status quo by adopting best practice from elsewhere, but there are some elements of churn that should be guarded against. In particular, there is a concern that churn results from a lack of devoting the full resources required for implementation. There is a large literature on policy implementation therefore we know to some extent what is needed. Future research could explore if there is a relationship between good implementation and low transfer. 
According to Peck (2001; p. 452): "the continued churning of policy strategies tends to (over)stretch the capacities and diffuse the energy of oppositional movements, rather than opening up the space for more progressive local initiatives." This also relates to the disagreement about whether increasing devolution and regionalism is good because it enables bottom-up processes for regions to activate new policies for economic development, versus the other view contending that it is just more churn that does not address the restrictions imposed by the unchanged system logic. The framework developed in this paper can aid the identification and analysis of this distinction, by gathering evidence against the key influencing factors.

Three research agendas can be derived from this paper. First, the need for an empirical analysis of policy churn using the framework developed in this paper, recognising the methodological challenges already discussed. Second, to identify whether there is a trend of the kinds of policies that are more or less likely to be churned, the types of institutional settings that lead to greater or lesser churn and whether there is a link between policy churn and a reluctance to devote the necessary resources to implementation. The role of legitimacy in the wider political activities and narratives of transport and other organisations could be explored in greater depth, including the role of political cycles and the normative aspects of defining policy failure. Finally, a number of related research topics can be derived from the preceding discussion, such as the relationship between politicians and planners in policy development and implementation, the relationship between policy/strategy documents and policy implementation and the use of expert knowledge in both formulating policy directly and transferring policies from elsewhere. Therefore, the framework developed in this paper is useful not only in its full form but also as a background against which to explore a number of individual elements.

\section{Acknowledgements}

I would like to thank the three anonymous reviewers who engaged closely with the paper and gave positive suggestions that produced a stronger final version.

\section{References}

Aldred, R. (2012). Governing transport from welfare state to hollow state: the case of cycling in the UK. Transport Policy. 23: 95-102. 
Banister, D. (2011). The trilogy of distance, speed and time. Journal of Transport Geography. 19: 950-959.

Bennett, C. J. (1991). What is policy convergence and what causes it? British Journal of Political Science. 21 (4): 215-233.

Bray, D. J., Taylor, M. A. P., Scrafton, D. (2011). Transport policy in Australia - Evolution, learning and policy transfer. Transport Policy. 18: 522-532.

Bulmer, S., Padgett, S. (2004). Policy transfer in the European Union: an institutionalist perspective. British Journal of Political Science. 35 (1): 103-126.

Cass, N., Faulconbridge, J. (2016). Commuting practices: new insights into modal shift from theories of social practice. Transport Policy. 45: 1-14.

Cerna, L. (2013). The Nature of Policy Change and Implementation: A Review of Different Theoretical Approaches. Paris: OECD.

Cerny, P. (1992). The changing architecture of politics. Structure, agency, and the future of the state. London: Sage.

Chaney, P. (2014). Mixed-methods analysis of political parties' manifesto discourse on rail transport policy: Westminster, Scottish, Welsh and Northern Irish elections 1945-2011. Transport Policy. 35: 275-285.

Codagnone, C., Misuraca, G., Savoldelli, A., Lupiañez-Villanueva, F. (2015). Institutional isomorphism, policy networks, and the analytical depreciation of measurement indicators: The case of the EU e-government benchmarking. Telecommunications Policy. 39 (3-4): 305-319.

De Jong, M., Geerlings, H. (2005). Exchanging experiences in transport infrastructure policies between Denmark and the Netherlands. International Journal of Technology, Policy and Management. 5 (2): 181-199.

DiMaggio, P. J., Powell, W. W. (1983). The iron cage revisited: institutional isomorphism and collective rationality in organization fields. American Sociological Review. 48 (2): 147-160.

Docherty, I., Shaw, J. (2011). The transformation of transport policy in Great Britain? 'New Realism' and New Labour's decade of displacement activity. Environment \& Planning A. 43 (1): 224-251.

Docherty, I., Shaw, J., Gather, M. (2004). State intervention in contemporary transport. Journal of Transport Geography. 12: 257-264. 
Docherty, I., Shaw, J., Gray, D. (2007). Transport strategy in Scotland since devolution. Public Money \& Management. 27 (2): 141-148.

Dolowitz, D., Marsh, D. (1996). Who learns from whom: a review of the policy transfer literature. Political Studies. 44 (2): 343-357.

Dolowitz, D., Marsh, D. (2000). Learning from abroad: the role of policy transfer in contemporary policymaking. Governance. 13 (1): 5-24.

Dunlop, C. (2009). Policy transfer as learning: capturing variation in what decision makers learn from epistemic communities. Policy Studies. 30 (3): 289-311.

Evans, M. (2009). Policy transfer in critical perspective. Policy Studies. 30 (3): 243-268.

Evans, M., Davies, J. (1999). Understanding policy transfer: a multi-level, multi-disciplinary perspective. Public Administration. 77 (2): 361-385.

Farmer, S. (2011). Uneven public transportation development in neoliberalizing Chicago, USA. Environment and Planning A. 43: 1154-1172.

Giddens, A. (1979). Central problems in social theory: action, structure and contradiction in social analysis. Berkeley, CA: University of California Press.

Giddens, A. (1984). The constitution of society. Berkeley, CA: University of California.

Goodwin, M., Jones, M., Jones, R. (2005). Devolution, constitutional change and economic development: explaining and understanding the new institutional geographies of the British state. Regional Studies. 39 (4): 421-436.

Goulden, M., Ryley, T., Dingwall, R. (2014). Beyond 'predict and provide': UK transport, the growth paradigm and climate change. Transport Policy. 32: 139-147.

Gudmundsson, H., Wyatt, A., Gordon, L. (2005). Benchmarking and sustainable transport policy: learning from the BEST network. Transport Reviews. 25 (6): 669-690.

Haas, E. (1980). Why collaborate? Issue linkage and international regimes. World Politics. 32: $357-405$.

Hall, P. (1993). Policy paradigms, social learning, and the state: the case of economic policymaking in Britain. Comparative Politics. 25 (3): 275-296.

Headicar, P. (2009). Transport Policy and Planning in Great Britain. Abingdon, Oxon: Routledge.

Heichel, S., Pape, J., Sommerer, T. (2005). Is there convergence in convergence research? an overview of empirical studies on policy convergence. Journal of European Public Policy. 12 (5): 817-840. 
Henderson, J. (2011). Level of service: the politics of reconfiguring urban streets in San Francisco, CA. Journal of Transport Geography. 19: 1138-1144.

Hess, F. M. (1999). Spinning wheels: the politics of urban school reform. Washington DC: Brookings Institution.

Howlett, M., Cashore, B. (2009). The dependent variable problem in the study of policy change: understanding policy change as a methodological problem. Journal of Comparative Policy Analysis. 11 (1): 33-46.

Hrelja, R. (2011). The tyranny of small decisions: unsustainable cities and local day-to-day transport planning. Planning Theory and Practice. 12 (4): 511-524.

Isaksson, K., Richardson, T. (2009). Building legitimacy for risky policies: the cost of avoiding conflict in Stockholm. Transportation Research Part A. 43: 251-257.

Ison, S., Rye, T., 2003. Lessons from travel planning and road user charging for policymaking: through imperfection to implementation. Transport Policy. 10 (3): 223-233.

Jarvis, D. S. L. (2014). Policy transfer, neoliberalism or coercive institutional isomorphism? Explaining the emergence of a regulatory regime for quality assurance in the Hong Kong higher education sector. Policy and Society. 33: 237-252.

Jessop, B. (2001). Institutional (re)turns and the strategic-relational approach. Environment \& Planning A. 33 (7): 1213-1235.

Jones, R., Goodwin, M., Jones, M., Simpson, G. (2004). Devolution, state personnel and the production of new territories of governance in the United Kingdom. Environment \& Planning A. 36 (1): 89-109.

Levi-Faur, D., Vigoda-Gadot, E. (2006). New public policy, new policy transfers: some characteristics of a new order in the making. International Journal of Public Administration. 29 (4): 247-262.

Lodge, M. (2003). Institutional choice and policy transfer: reforming British and German railway regulation. Governance. 16 (2): 159-178.

MacKinnon, D., Shaw, J., Docherty, I. 2010. Devolution as process: institutional structures, state personnel and transport policy in the United Kingdom. Space and Polity. 14 (3): 271-287.

Marschall, M., Shah, P. (2005). Keeping policy churn off the agenda: urban education and civic capacity. The Policy Studies Journal. 33 (2): 161-180. 
Marsden, G., Frick, K. T., May, A. D., Deakin, E. (2011). How do cities approach policy innovation and policy learning? A study of 30 policies in Northern Europe and North America. Transport Policy. 18: 501-512.

Marsden, G., Frick, K. T., May, A. D., Deakin, E. (2012). Bounded rationality in policy learning amongst cities: lessons from the transport sector. Environment and Planning A. 44: 905-920.

Marsden, G., Mullen, C., Bache, I., Bartle, I., Flinders, M. (2014). Carbon reduction and travel behaviour: discourses, disputes and contradictions in governance. Transport Policy. 35: 71-78.

Marsden, G., Stead, D. (2011). Policy transfer and learning in the field of transport: a review of concepts and evidence. Transport Policy. 18:492-500.

Marsh, D., Sharman, J. C. (2009). Policy diffusion and policy transfer. Policy Studies. 30 (3): 269-288.

McCann, E., Ward, K. (2013). A multi-disciplinary approach to policy transfer research: geographies, assemblages, mobilities and mutations. Policy Studies. 34 (1): 2-18.

Meyer, J. W., Rowan, B. (1977). Institutionalized organizations: formal structure as myth and ceremony. American Journal of Sociology. 83 (2): 340-363.

Monios, J. (2014). Institutional challenges to intermodal transport and logistics. Ashgate: London.

Monios, J., Lambert, B. (2013). The heartland intermodal corridor: public-private partnerships and the transformation of institutional settings. Journal of Transport Geography. 27 (1): 36-45.

Mononen, P., Leviäkangas, P. (2016). Transport safety agency's success indicators - how well does a performance management system perform? Transport Policy. 45: 230-239.

Morphet, J., Clifford, B. (2014). Policy convergence, divergence and communities: the case of spatial planning in post-devolution Britain and Ireland. Planning, Practice \& Research. 29 (5): 508-524.

Naess, P., Hansson, L., Richardson, T., Tennøy, A. (2013). Knowledge-based land use and transport planning? Consistency and gap between "state-of-the-art" knowledge and knowledge claims in planning documents in three Scandinavian city regions. Planning Theory and Practice. 14 (4): 470-491.

Newman, P. (2008). Strategic spatial planning: collective action and moments of opportunity. European Planning Studies. 16 (10): 1371-83. 
O'Dolan, C., Rye, T. (2012). An insight into policy transfer processes within an EU project and implications for future project design. Transport Policy. 24: 273-283.

Oliver, C. (1991). Strategic responses to institutional processes. Academy of Management Review. 16 (1): 145-179.

Paget-Seekins, L. (2015). Bus rapid transit as a neoliberal contradiction. Journal of Transport Geography. 48: 115-120.

Parnell, P., Robinson, J. (2012). (Re)theorizing cities from the Global South: Looking beyond neoliberalism. Urban Geography. 33 (4): 593-617.

Peck, J. (2001). Neoliberalizing states: thin policies/ hard outcomes. Progress in Human Geography. 25 (3): 445-455.

Peck, J. (2011). Geographies of policy: from transfer-diffusion to mobility-mutation. Progress in Human Geography. 35 (6): 773-797.

Peck, J., Theodore, N. (2001). Exporting workfare/importing welfare-to-work: exploring the politics of Third Way policy transfer. Political Geography. 20: 427-460.

Peck, J., Theodore, N., Brenner, N. (2009). Neoliberal urbanism: models, moments, mutations. SAIS Review. 29 (1): 49-66.

Pierson, P. (2004). Politics in time: history, institutions and social analysis. Princeton, NJ: Princeton University Press.

Radaelli, C. M. (2000). Policy Transfer in the European Union: Institutional Isomorphism as a Source of Legitimacy. Governance. 13 (1): 25-43.

Rhodes, R. A. W. (1994). The Hollowing out of the State: The Changing Nature of the Public Service in Britain. The Political Quarterly. 65: 138-51.

Robertson, D. B. (1991). Political conflict and lesson-drawing. Journal of Public Policy. 11 (1): 55-78.

Rose, R. (1991). What is lesson drawing? Journal of Public Policy. 11: 1.

Rose, R. (1993). Lesson Drawing in Public Policy. Chatham, NJ: Chatham House.

Rye, T., Welsch, J., Plevnik, A., de Tommasi, R. (2011). First steps towards cross-national transfer in integrating mobility management and land use planning in the EU and Switzerland. Transport Policy. 18: 533-543.

Schwanen, T., Banister, D., Anable, J. (2012). Rethinking habits and their role in behaviour change: the case of low-carbon mobility. Journal of Transport Geography. 24: 522-532.

Shaw, J., MacKinnon, D., Docherty, I. (2009). Divergence or convergence? Devolution and transport policy in the United Kingdom. Environment \& Planning C. 27 (3): 546-567. 
Stead, D. (2008). Institutional aspects of integrating transport, environment and health policies. Transport Policy. 139-148.

Stead, D., de Jong, M., Reinholde, I. (2008). Urban transport policy transfer in Central and Eastern Europe. disP - The Planning Review. 172 (1): 62-73.

Stone, J. (2014). Continuity and change in urban transport policy: politics, institutions and actors in Melbourne and Vancouver since 1970. Planning, Practice and Research. 29 (4): $388-404$.

Tennøy, A. (2010). Why we fail to reduce urban road traffic volumes: does it matter how planners frame the problem? Transport Policy. 17: 216-233.

Tennøy, A., Hansson, L., Lissandrello, E., Næss, P. (2015). How planners' use and non-use of expert knowledge affect the goal achievement potential of plans: Experiences from strategic land-use and transport planning processes in three Scandinavian cities. Progress in Planning. In press.

Timms, P. (2011). Urban transport policy transfer: "bottom-up" and "top-down" perspectives. Transport Policy. 18: 513-521.

Weiss, L. (2012). The myth of the neoliberal state. In C. Kyung-Sup, B. Fine, \& L. Weiss (Eds.), Developmental politics in transition: The neoliberal era and beyond (1st ed., pp. 27-42). New York: Palgrave Macillan.

Wilmsmeier, G., Monios, J. (2016). Institutional structure and agency in the governance of spatial diversification of port system evolution in Latin America. Journal of Transport Geography. 51: 294-307.

Wolman, H., Page, E. (2002). Policy transfer among local governments: an information theory approach. Governance. 15 (4): 477-501. 